\title{
Simulation of a Cold Store Driven by Solar Absorption Cooling System under Different Egyptian Climatic Conditions
}

\author{
$\{\text { M. Abd El.hamed*, A. Mostafa, M. Fatouh }\}^{\dagger}$
}

\begin{abstract}
Storing of products at their recommended storage temperatures in a cold store is expensive due to their cost of electricity consumption. In order to avoid the drawbacks of both fossil fuels shortage and chlorofluorocarbon refrigerants, the substitution of a conventional vapor compression refrigeration system by a solar absorption cooling system is a promising alternative to operate the cold stores. Therefore, the main objective of the present work is to simulate and evaluate the performance of solar powered absorption refrigeration system to operate the cold store under Egyptian climatic conditions. To achieve this objective, a simulation model based on the mass and energy conservation equations is developed using TRNSYS software. The results showed that this model predicts data that are very close to the available data in the literature with an average error of $6.21 \%$. The results indicated that the maximum load is $7.12 \mathrm{~kW}$ in 21 - July. Reported results revealed that solar collector area of 100 $\mathrm{m}^{2}$ and storage tank volume of $1.8 \mathrm{~m}^{3}$ are required for a maximum cold store load with solar fraction of 0.75 .
\end{abstract}

Keywords: Solar absorption chiller, Cold store, evacuated-tube collector

\section{Introduction}

When fruits and vegetables are harvested, they are cut off from their source of water and nutrition and soon start to deteriorate. They lose weight, texture, flavor, nutritive value and appeal. Both time and temperature are important factors in post-harvest product deterioration. Experts estimate that, worldwide, more than one-third of all perishable goods never reach the consumer due to lack of preservation facilities in producing farms and consuming centers [1]. Cooling the harvested products, using a cold store, control the rate of quality loss by slowing the rate of respiration [2,3]. The cold storage is a building with thermal insulation and a refrigerating system in which perishable agriculture products can be stored for different times with a required condition of temperature and humidity. Such storage under controlled conditions decreases the rate of deterioration and spoilage that would naturally occur in an uncontrolled natural environment. However, the majority of refrigeration systems employs vapor compression equipment, which leads to significant economic losses. Also, the forecast energy shortage coupled with the environmental problems associated with conventional energy generation and the rapid increase in world population provide a strong motivation for a muchexpanded clean energy supply [4]. For this reason, different alternatives to reduce electrical consumption should be used. Thus, solar absorption cooling system becomes an interesting alternative to be studied due to the tremendous solar potential in Egypt taking in account that the thermal cooling load increases when the solar radiation is maximum.

m.abedo2005@hotmail.com

$\dagger$ Mechanical Power Engineering Department, Faculty of Engineering, Mataria, Helwan University P.O., 11718 Cairo, Egypt. 
In the past decade, several solar driven absorption cooling systems have been proposed, developed and tested at many different locations around the world. These studies have demonstrated that the most efficient (cost and performance) collector type in solar cooling systems is the evacuated tube collector which allows the reduction in $50 \%$ of the collector surface compared to the flat plate collectors $[5,6,7,8]$. Moreover, the utilization of hot water storage tank and an auxiliary heater make sure that the required temperatures are available at any time of the day [9].

Despite the many reported investigations, simulation of solar driven absorption refrigeration system for a cold store needs to be investigated under Egyptian weather conditions. The present research aims at evaluating the performance of a solar driven absorption refrigeration system for a $40 \mathrm{~m}^{3}$ cold storage space designed to store tomatoes under Cairo weather conditions. Simulation of a system using TRNSYS software is carried out. Then, a verification of the model with the available literature data is established. Finally, Energetic analysis of the system under Cairo weather conditions is conducted using Engineering Equation Solver (EES) software.

\section{System Description}

The proposed system consists of three main subsystems: the solar heating subsystem, the absorption cooling subsystem and the cold store as shown in Fig. 1. The solar collectors absorb the incoming solar radiation, convert it into heat and transfer this heat to the fluid flowing through the collector. The collected solar energy is transferred from the circulating fluid to the absorption system using a pump. The storage tank is added to the system to shift the excess thermal energy as much as possible from the periods of high solar availabilities to the periods of low solar availabilities. An additional heater is used when the temperature of the storage tank is lower than the required temperature of the generator.

If the outlet collector temperature is higher than the storage tank bottom temperature in more than $6^{\circ} \mathrm{C}$, a controller of the solar field pump is activated and deactivates when that temperature difference is less than $2{ }^{\circ} \mathrm{C}$. Also, the controller used to keep the maximum outlet temperature from the tank about $94{ }^{\circ} \mathrm{C}$ (maximum inlet hot water temperature to the chiller) and the auxiliary heater is activated when the outlet temperature from the storage tank is less than $83^{\circ} \mathrm{C}$ to rise the temperature to $88^{\circ} \mathrm{C}$. After that, the hot water flows to the absorption chiller generator. Then, the cooling water from a cooling tower flows into the absorption chiller to cool the condenser and absorber as shown in Fig. 2. The absorption machine was a Yazaki WFC SC 50 with $17.5 \mathrm{~kW}$ of nominal power represented by the "Type 107" [10] and the technical specifications of the used absorption chiller is shown in Table 1.

Table 1. Technical specifications of absorption machine

\begin{tabular}{|l|l|l|}
\hline Cooling capacity & $17.5 \mathrm{~kW}$ & \multicolumn{2}{|c|}{} \\
\hline \multirow{4}{*}{ Hot water } & Rated Inlet temperature & $88^{\circ} \mathrm{C}$ \\
\cline { 2 - 3 } & Rated Outlet temperature & $83^{\circ} \mathrm{C}$ \\
\cline { 2 - 3 } & Rated flow rate & $1.198 \mathrm{~kg} / \mathrm{s}$ \\
\cline { 2 - 3 } & Max. operating pressure & $588 \mathrm{kPa}$ \\
\hline \multirow{5}{*}{ Cooling water } & Rated Inlet temperature & $31^{\circ} \mathrm{C}$ \\
\cline { 2 - 3 } & Rated Outlet temperature & $35^{\circ} \mathrm{C}$ \\
\cline { 2 - 3 } & Rated flow rate & $2.5 \mathrm{~kg} / \mathrm{s}$ \\
\cline { 2 - 3 } & Max. operating pressure & $588 \mathrm{kPa}$ \\
\hline \multirow{5}{*}{ Chilled water } & Rated Inlet temperature & $12.5^{\circ} \mathrm{C}$ \\
\cline { 2 - 3 } & Rated Outlet temperature & $7^{\circ} \mathrm{C}$ \\
\cline { 2 - 3 } & Rated flow rate & $0.76 \mathrm{~kg} / \mathrm{s}$ \\
\cline { 2 - 3 } & Max. operating pressure & $588 \mathrm{kPa}$ \\
\hline
\end{tabular}




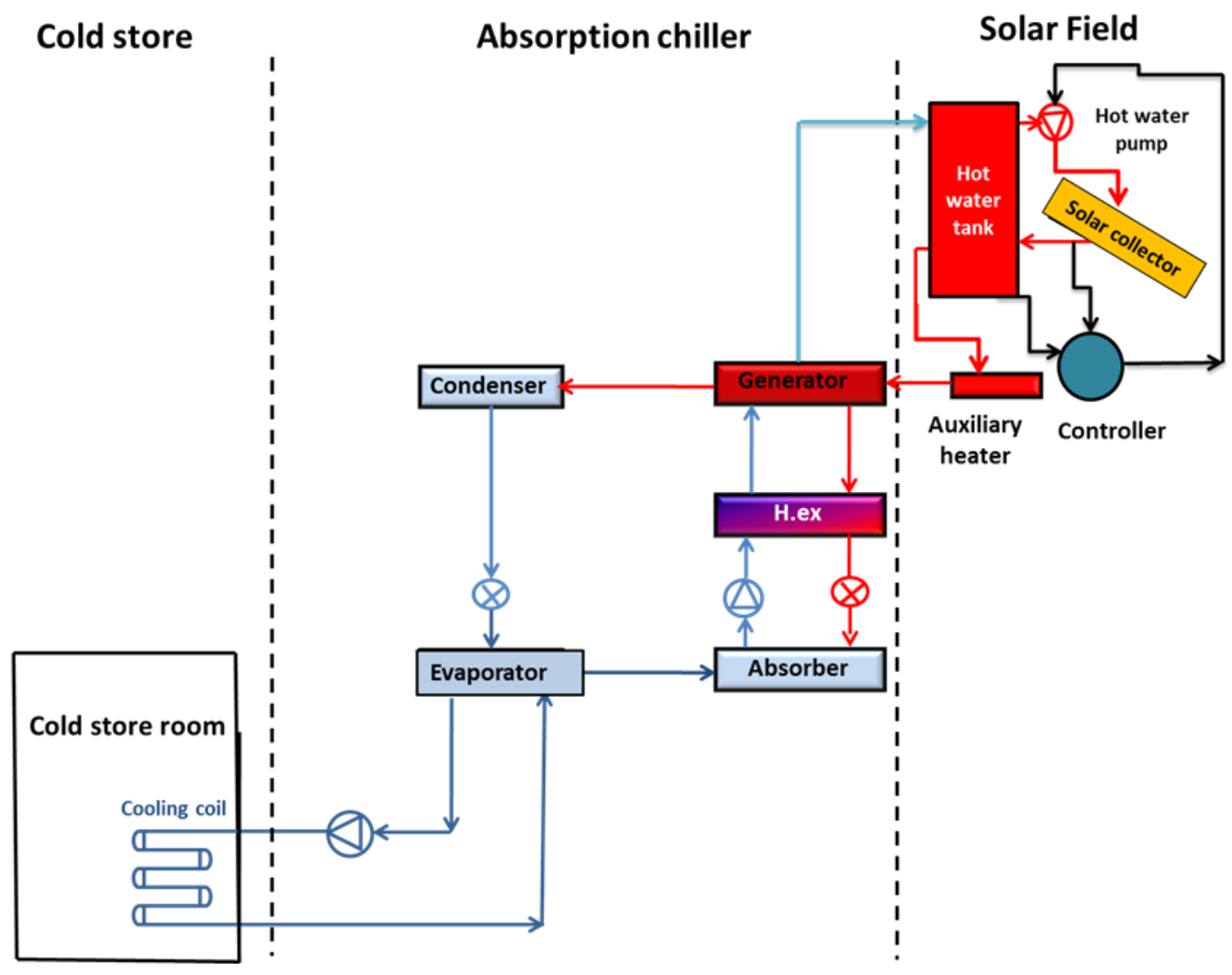

Fig. 1. Proposed solar absorption refrigeration system.

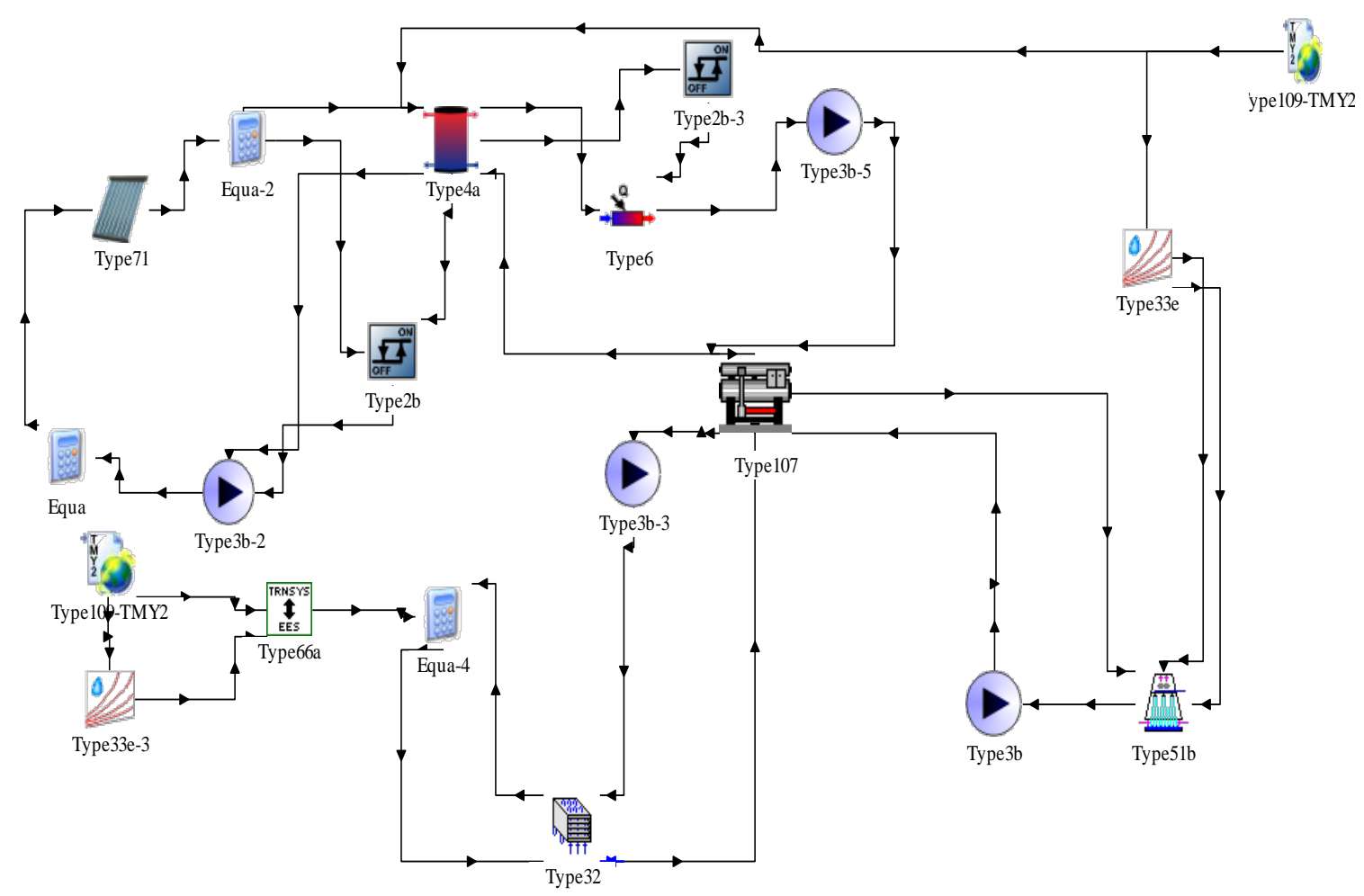

Fig.2. TRNSYS model of the proposed system 


\section{Methodology}

To design a refrigeration system, the heat load must be calculated. The major sources of heat in the cold store are 1) conduction through the walls, 2) respiration from the vegetables, 3) field heat and 4) service load generated from lights, fans and people coming in and out of the unit. The conduction heat gain through walls, floor and ceiling can be calculated as follows:

$$
Q_{T}=U \times A \times\left(T_{a m b}-T_{s t}\right)
$$

Where $\mathrm{U}$ is the overall heat transfer coefficient for the walls, floor and ceiling, $\mathrm{A}$ is the surface area of the cold store walls, floor and ceiling, $\mathrm{T}_{\mathrm{amb}}$ is the ambient temperature, $\mathrm{T}_{\mathrm{st}}$ is the required storage temperature for the product or the indoor temperature.

Heat of respiration for each vegetable is calculated by measuring how much $\mathrm{CO}_{2}$ is produced in a day and converting that to heat by the following equation.

$$
Q_{\text {resp }}=W \times R
$$

Where $\mathrm{W}$ is the product weight and $\mathrm{R}$ is the respiration rate for the product.

To calculate the field heat, the mass of produce, the specific heat and the temperature difference between the initial produce temperature and the temperature of the cellar where the produce will be stored is needed, i.e.

$$
Q_{\text {product }}=W \times c \times\left(T_{a m b}-T_{s t}\right)
$$

The final source of heat is the service load, which is due to operational factors such as doors opening/closing, lights, fans, and people working in the cellar. Due to the level of difficulty involved in calculating these heat sources, the service load is estimated as ten percent of the other heat sources.

Simulation of the absorption chiller, hot water tank, evacuated tube solar collector and controller are carried out using Transient Systems Simulation Program (TRNSYS) software [11]. Each type of component is described by a mathematical model in the TRNSYS simulation engine. TRNSYS type-107, type-4a, type-71 and type-2b are used to simulate the absorption chiller, hot water tank, evacuated tube solar collector and controller, respectively.

\section{Results and Discussion}

The present work deals with modeling and simulation of a solar driven absorption refrigeration system for a cold store. The results are presented under five titles: (i) model validation, (ii) variation of ambient conditions in summer season, (iii) cold store cooling load variation, (iv) effect of varying solar collector area and storage tank volume on solar fraction, (v) variation of daily solar fraction across summer season, (vi) system performance in the peak load day in each month, (iv) solar fraction during summer season, (v) System performance variation.

\section{(i) Model Validation}

Model validation is based on available data for chilled water temperature. Published data by Ssembatya M.et al. [11] are used to validate the present results as shown in Fig.3, which shows an acceptable agreement with an error of $6.21 \%$.

\section{(ii) Variation of Ambient Conditions}

Average ambient air dry-bulb temperature and relative humidity with the day during the four months of summer season in Cairo are shown in Figs.4 and 5, respectively. It is seen that the average dry-bulb temperature in Cairo in summer season ranges between $23^{\circ} \mathrm{C}$ and $32^{\circ} \mathrm{C}$ and the relative humidity lies between $42 \%$ to $62 \%$. 


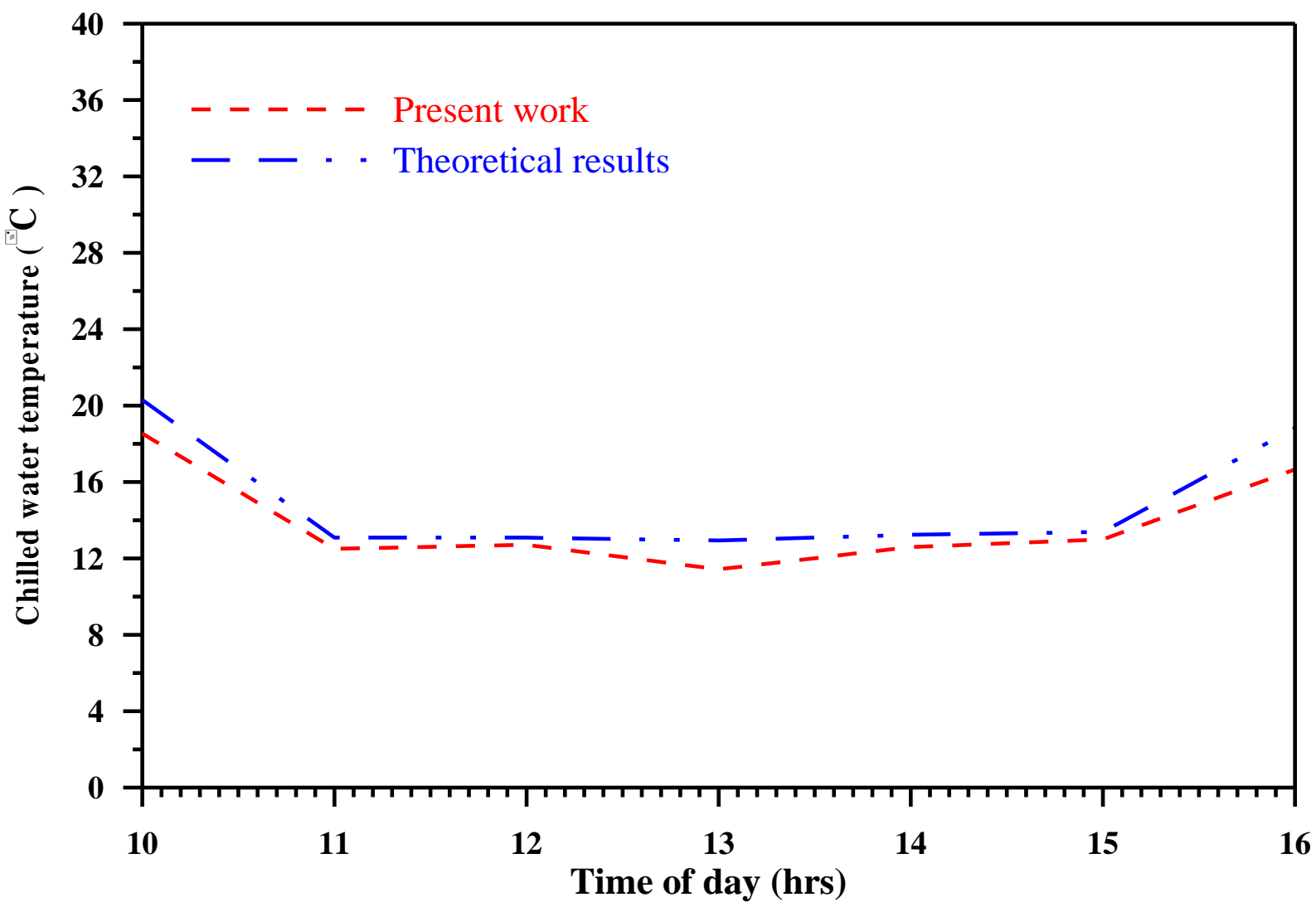

Fig.3. Chilled water for a typical day in April

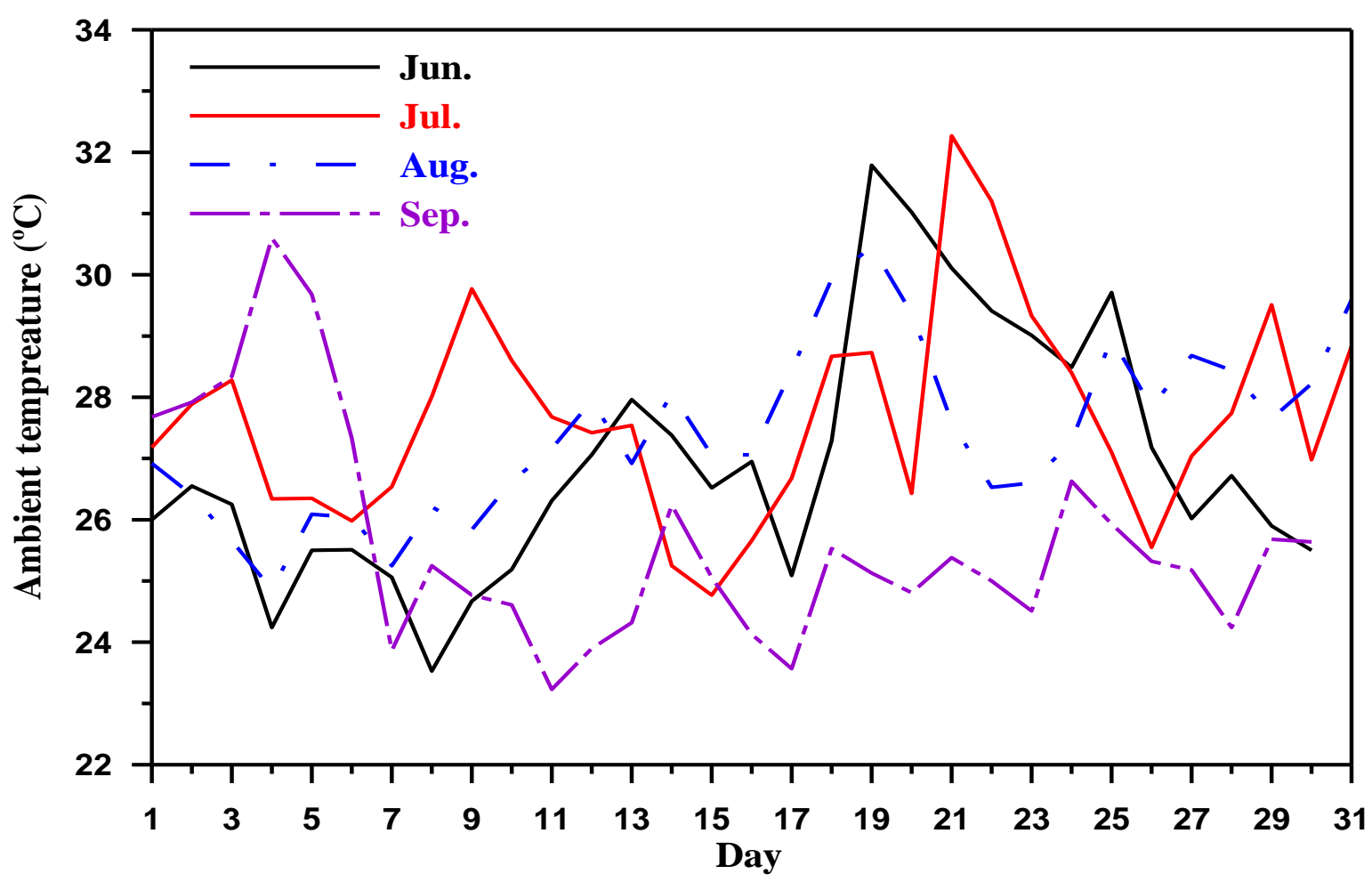

Fig.4. Ambient temperature during summer season months 


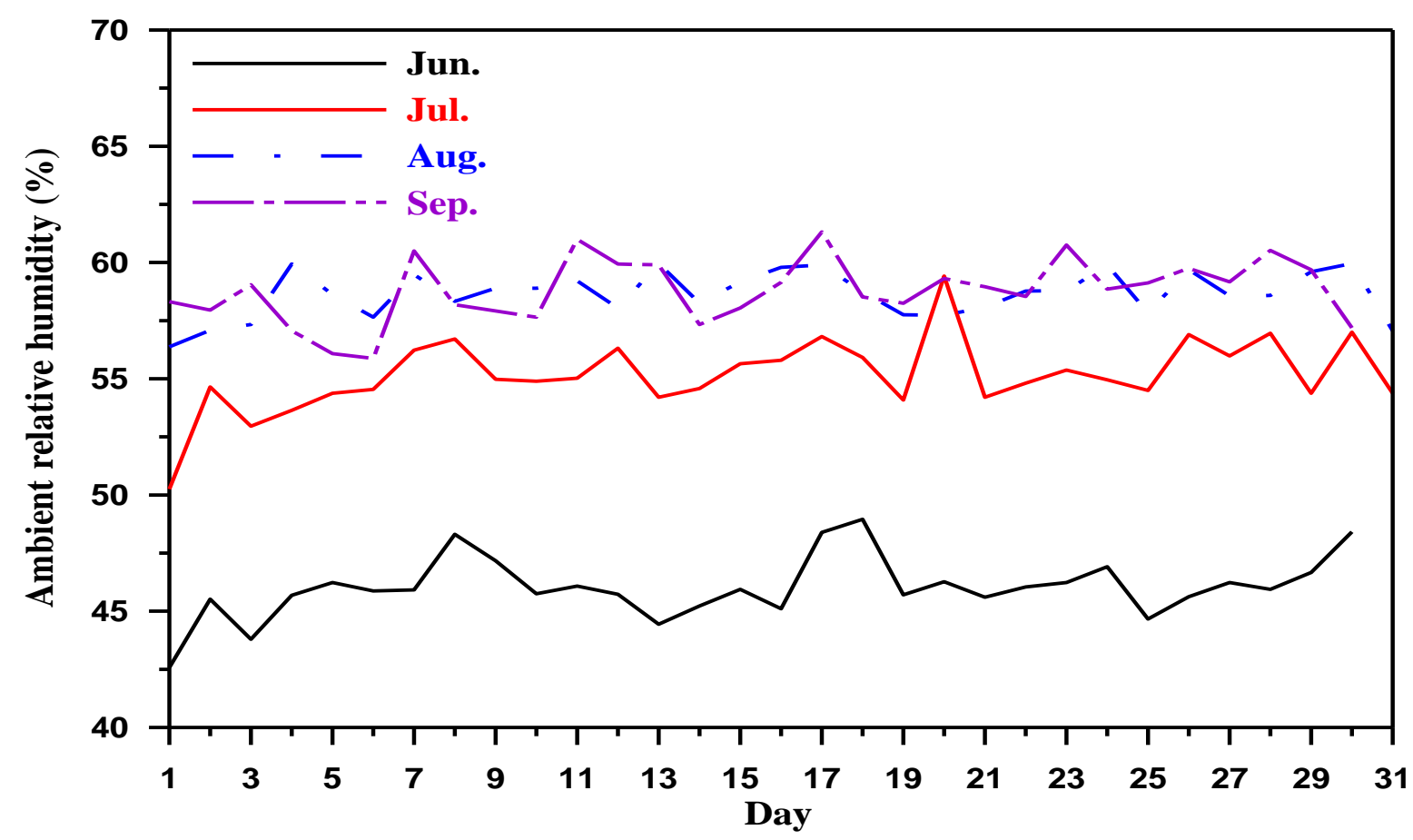

Fig.5. Relative humidity during summer season months

(iii) Cold Store Load Variation

Variation of cold store cooling load with day during the four months of summer season is presented in Fig.6. This figure confirms that, the average cold store cooling load variation is mainly due to the variation of ambient conditions. From the simulation results, the highest load during summer season is about $7.12 \mathrm{~kW}$ on 21 - July. Also, it has been shown that the ambient temperature increase plays an important role in cold store cooling load, which increases in the

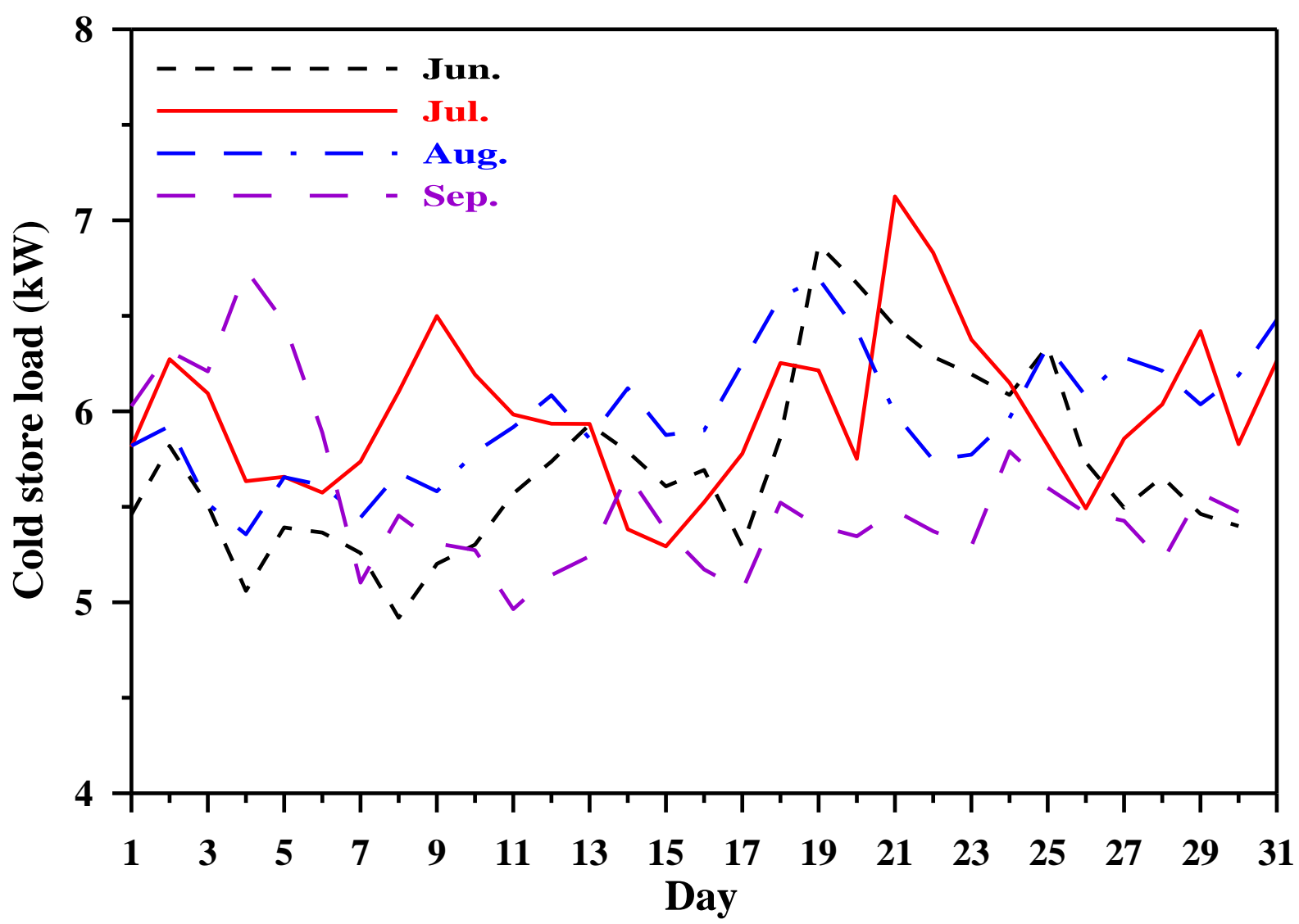

Fig.6. Cold store cooling load during the summer season months 
first three months of the summer season and decreases at the end of it due to the decrease of ambient temperature as shown in Fig.6. This figure reveals that, the maximum cooling load of cold store is $7.12 \mathrm{~kW}$ in July followed by $6.87 \mathrm{~kW}$ in June, $6.74 \mathrm{~kW}$ in September and $6.70 \mathrm{~kW}$ in August at storage temperature of $16^{\circ} \mathrm{C}$ and relative humidity of $90 \%$ which are the storage conditions of tomato [12].

\section{(iv) Solar Fraction During Summer Season}

Variation of solar fraction with the day during the summer season months is presented in Fig.7 to determine the maximum and minimum achieved daily solar fraction. According to the proposed values in the later section, a daily analysis for the system performance has been done in order to determine the maximum and minimum solar fraction where June, July and August have high solar fraction values while September has the lowest solar fraction. This is mainly due to high global solar radiation values in June, July and August and low global solar radiation in September. These results indicate that the system could achieve the highest daily solar fraction of 0.85 in August. Also, the minimum value for the solar fraction is 0.49 in September. The reason behind of solar fraction reduction is the decrease in the global solar radiation, so the system is less efficient and would mainly depend on the auxiliary heater.

\section{(v) System Performance Variation}

Hourly generator, storage tank and auxiliary heat transfer rates for the peak load day in each month is presented as shown in Fig.8. In order to analyze the hourly performance of the system, the results of the four months are shown in Fig.8. This analysis shows a comparison between the heat supplied to the generator from the tank and that from the auxiliary heater. It can be concluded that the supply of heat from the tank is proportional to the incident solar radiation in that day. Also, it can be noted that the auxiliary system is not needed in times of high solar radiation. But the auxiliary heater is needed to keep the hot water temperature at $88^{\circ} \mathrm{C}$.

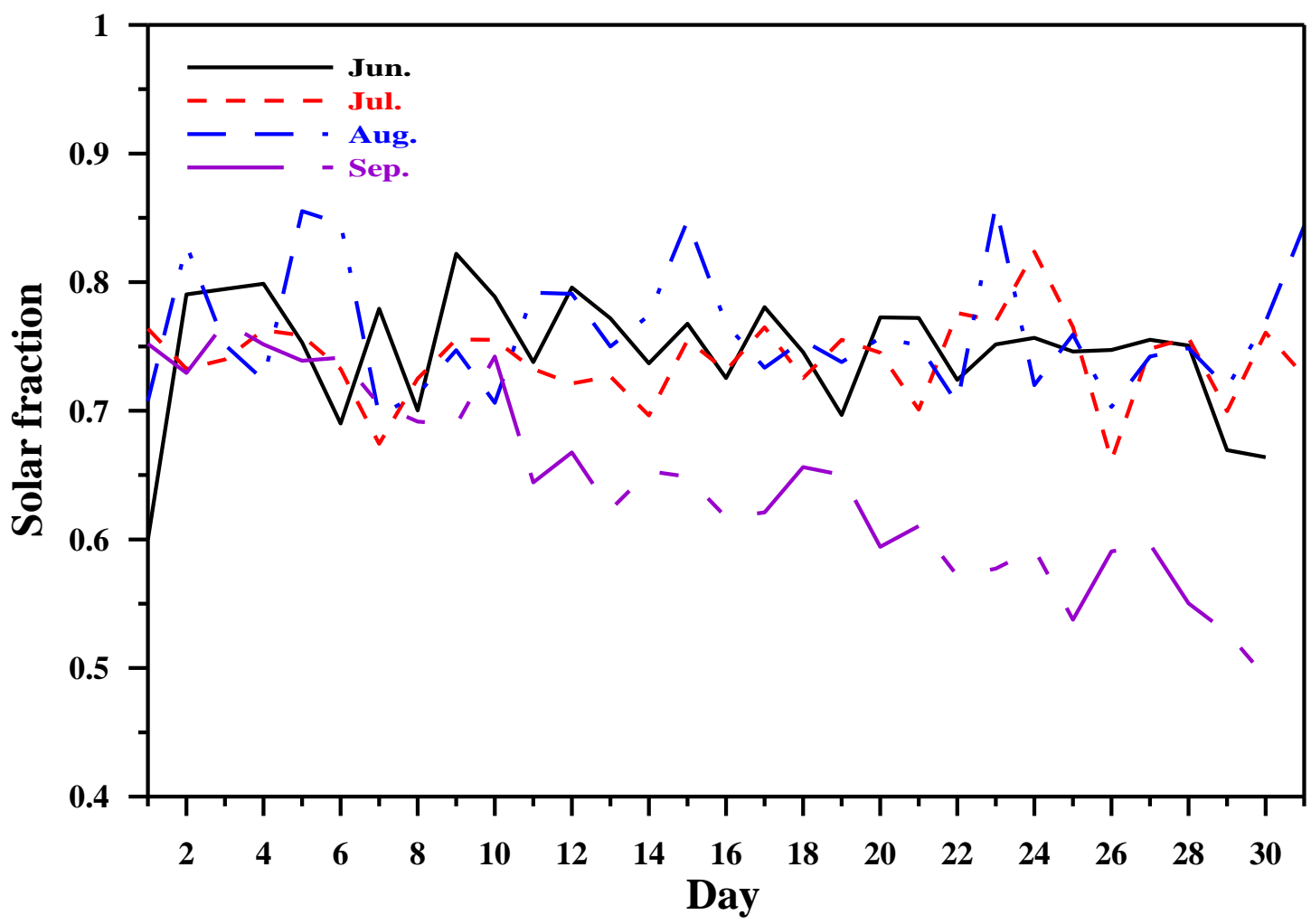

Fig.7. Daily Solar fraction for various summer month 
Also, it has been shown that the percentage of auxiliary heating rate from the total required heat by the generator reaches to $34 \%$ in the peak load day in September as the minimum solar fraction is achieved in this month and $21 \%$ in the peak load day in August as the maximum solar fraction is achieved in this month as shown in Fig. 8.
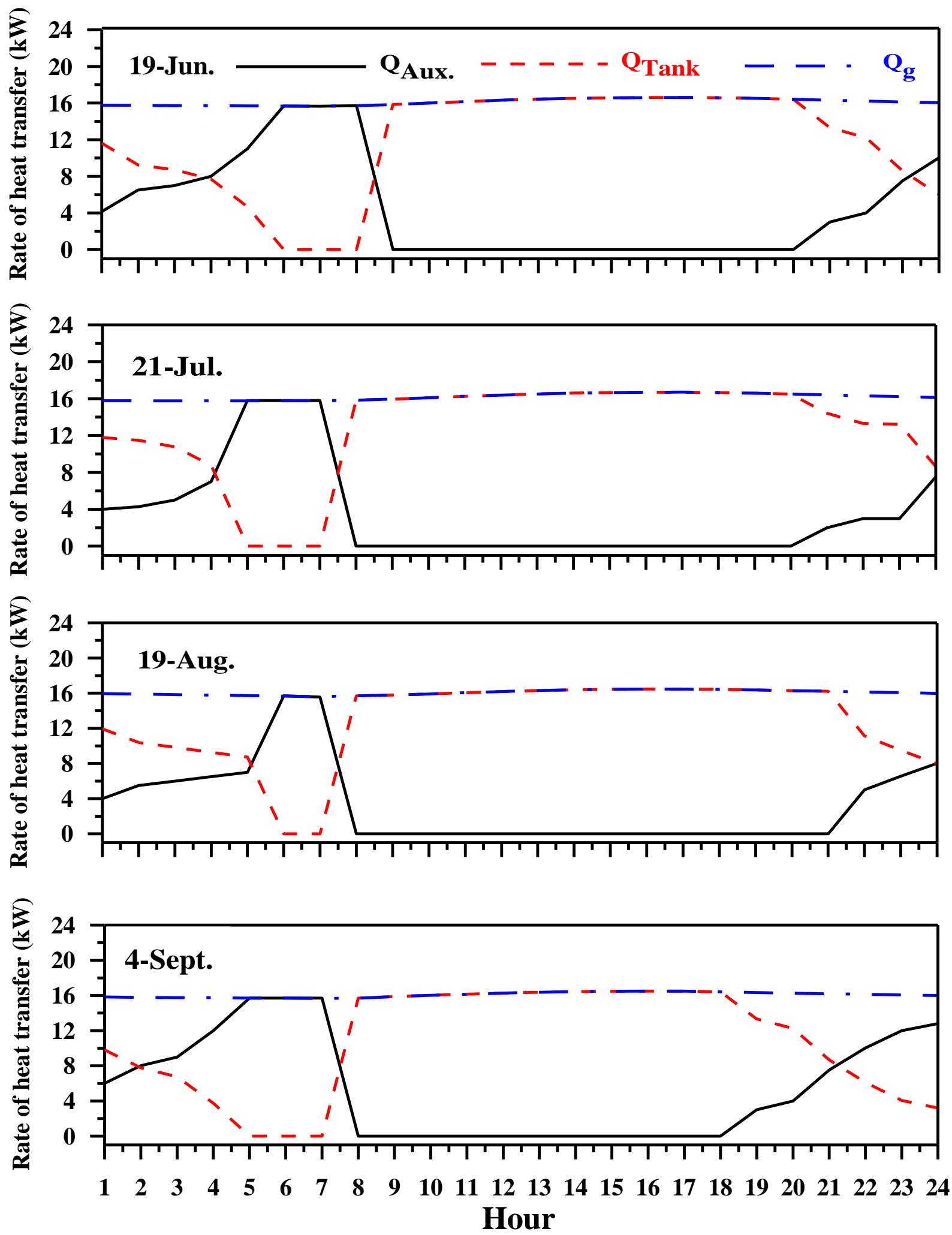

Fig.8. System performance for the peak load day in each month 


\section{Conclusions}

In the present work, modeling and simulation of a solar driven absorption refrigeration system for a cold store is carried out under Cairo weather conditions. Based on the simulation results, the following conclusions are drawn;

- Yearly solar fraction of up to 0.75 could be achieved during the summer season considering the optimal collector surface and hot water storage tank.

- Maximum cold store cooling load is about $7.12 \mathrm{~kW}$ in July.

- The solar fraction increases with increasing collector area and storage tank volume achieving a maximum daily solar fraction reaches to 0.85 .

- Optimal collector surface area and hot water storage tank volume are $100 \mathrm{~m}^{2}$ and $1.8 \mathrm{~m}^{3}$, respectively.

- The percentage of auxiliary heating rate is nearly $34 \%$ and $21 \%$ for the peak load in September and August, respectively.

- The auxiliary heater is required to keep the hot water temperature at $88^{\circ} \mathrm{C}$ from $6 \mathrm{pm}$ to 7 am with different rates based on the amount of the energy stored in the tank during summer season.

\section{Acknowledgements}

The authors are grateful acknowledge the Science and Technology Development Fund in Egypt (STDF).

\section{References}

[1] Jog K. V., "Cold Storage Industry in India". Keynote presentation at conference of Refrigerated Warehouse \& Transport Association of Australia (RWTA) Melbourne, Australia. 2004.

[2] Arvind O.S., "An overview of cold storage practices in India". Taraporeva, D.B. sons \& co. private limited company. 1967.

[3] Agyenim F. B., "The development of medium temperature thermal energy storage for cooling applications", University of Ulster, 2007.

[4] Grossman G. and Zaltash A., "ABSIM - modular simulation of advanced absorption systems". International Journal of Refrigeration. 24, 2001;(6): p. 531-543.

[5] Sumathy K., Huang Z. C., and Li Z. F., "Solar absorption cooling with low grade heat source - a strategy of development in South China". Solar Energy. 72, 2002;(2): p. 155165.

[6] Balghouthi M., Chahbani M. H., and Guizani A., "Investigation of a solar cooling installation in Tunisia". Applied Energy. 98, 2012: p. 138-148.

[7] Asdrubali F. and Grignaffini S., "Experimental evaluation of the performances of a $\mathrm{H} 2 \mathrm{O}-$ $\mathrm{LiBr}$ absorption refrigerator under different service conditions". International Journal of Refrigeration. 28, 2005;(4): p. 489-497.

[8] Mateus T. and Oliveira A. C., "Energy and economic analysis of an integrated solar absorption cooling and heating system in different building types and climates". Applied Energy. 86, 2009;(6): p. 949-957.

[9] Yazaki E. S., "WFC-SC(H) chiller and chiller-heater, Service Manual Section 1, Specifications WFC-SC(H)10, 20, 30, http://www.yazakienergy.com". 2008.

[10] Klein S. A., Beckman W.A., and Duffie J. A., "TRNSYS: A Transient System Simulation Program".Solar Energy Laboratory, University of Wisconsin--Madison, USA, 2000.

[11] Ssembatya M., Pokhrel M. K., and Reddy R., "Simulation Studies on Performance of Solar Cooling System in UAE Conditions". Energy Procedia. 48, 2014: p. 1007-1016.

[12] ASHRAE, "Handbook of HVAC Systems and Equipment".American Society of Heating, Refrigerating and Air-Conditioning Engineers, Inc., Atlanta, GA, 2010. 